\title{
El derecho fundamental a la igualdad y no discriminación en la jurisprudencia del Tribunal Constitucional del Perú ${ }^{1}$
}

\author{
The Human Right to Equality and non- discrimination in the Peruvian \\ Constitutional Court Case Law
}

César LANDA ARROYO²

\begin{abstract}
Resumen: La igualdad y la no discriminación forman parte de los cimientos de nuestro Orden Constitucional y comprenden un principio y derecho fundamental que irradia las relaciones horizontales y verticales de nuestro ordenamiento jurídico.

En este artículo, el autor analiza la línea jurisprudencial del Tribunal Constitucional sobre la igualdad y no discriminación en el Perú, lo que ha determinado el ejercicio y goce de los derechos fundamentales de los colectivos históricamente discriminados. Es imperativo el análisis de esta materia, ya que la discriminación ha estado presente desde los inicios de la historia: es un problema estructural e interseccional.
\end{abstract}

Palabras clave: Derecho Constitucional, Tribunal Constitucional, Igualdad, No discriminación, Grupos en situación de especial vulnerabilidad, Jurisprudencia

\begin{abstract}
Equality and non-discrimination are part of the foundations of our Constitutional Order, comprising a fundamental principle and right that irradiates the horizontal and vertical relations of our legal system. In this article, the author analyzes the jurisprudential line of the Constitutional Court on equality and non-discrimination in Peru, which has determined the exercise and enjoyment of the fundamental rights of historically discriminated groups. The analysis of this issue is imperative, since discrimination has been present since the beginning of history, being a structural and intersectional problem.
\end{abstract}

\footnotetext{
${ }^{1}$ El artículo forma parte del proyecto de investigación "Contribución de la jurisprudencia del Tribunal Constitucional a la afi rmación del derecho a la igualdad y no discriminación para grupos en situación de especial vulnerabilidad en el Perú", auspiciado por el Vicerrectorado de Investigación de la Pontificia Universidad Católica del Perú (proyecto 570).

2 Profesor de Derecho Constitucional de la Pontificia Universidad Católica del Perú y la Universidad Nacional Mayor de San Marcos. Expresidente del Tribunal Constitucional del Perú. Integrante del Grupo de Investigación en Derecho Constitucional y Derechos Fundamentales, del Área de Derecho Constitucional - PUCP. Código ORCID: 0000-0003-0801-8873. Lugar de Residencia: Lima, Perú. Correo electrónico: clanda@pucp.edu.pe
} 
Keywords: Constitutional Law, Constitutional Court, Equality, No discrimination, Groups in a situation of special vulnerability, Jurisprudence

\section{Introducción}

El presente trabajo tiene como finalidad realizar una reflexión crítica en torno a la concepción que tiene el Tribunal Constitucional del Perú sobre el derecho a la igualdad y a la no discriminación, para lo cual se postula una metodología de análisis jurisprudencial práctica a partir de las sentencias emitidas entre los años 2001 y 2016. Por sus propias limitaciones, este estudio no revisará toda la jurisprudencia del Tribunal, sino aquella que contiene los desarrollos más relevantes y emblemáticos en materia de igualdad y no discriminación, porque trazan una línea jurisprudencial que luego ha sido replicada por el propio alto tribunal en otros casos.

Al respecto, la hipótesis del estudio es que el Tribunal Constitucional ha avanzado en una primera etapa en el uso de la igualdad como un principio de interpretación, incluido el test de la igualdad, y en una segunda etapa ha desplegado una incipiente doctrina jurisprudencial de las categorías de la discriminación, pero que se ha hecho evidente apenas en la tutela de los derechos de los grupos vulnerables, debido a un déficit de congruencia argumentativa,

Para lograr el objetivo propuesto, se presentarán las principales ideas que el Tribunal ha ido desarrollando sobre el derecho a la igualdad, así como se realizará un análisis crítico, en términos generales, de las sentencias sobre igualdad y no discriminación que servirá para una mejor comprensión de la aplicación específica del tratamiento de la igualdad en relación con poblaciones vulnerables sobre las que el Tribunal haya resuelto casos específicos: mujeres y niñas; reclusos; pueblos indígenas; personas con discapacidad mental y población LGTBI+.

\section{Aproximación a la naturaleza de la igualdad y la no discriminación en la jurisprudencia del Tribunal Constitucional: ¿es solo un derecho fundamental?}

Si bien la igualdad se encuentra recogida en el título relativo a los derechos fundamentales de la persona (artículo 2.23), con lo cual podríamos indicar que es un derecho subjetivo fundamental, la jurisprudencia del Tribunal Constitucional le ha reconocido también el carácter de principio constitucional que caracteriza al modelo de Estado que ha configurado la

${ }^{3}$ Constitución Política del Perú (1993). 
Constitución de 1993 “(...) la igualdad, además de ser un derecho fundamental, es también un principio rector de la organización del Estado Social y Democrático de Derecho y de la actuación de los poderes públicos"4.

Como principio, la igualdad tiene un reconocimiento transversal en el texto constitucional de 1993, dado que, además de ser concebido como un derecho fundamental, en tanto principio constitucional establece las directrices para el diseño de políticas públicas a cargo del Estado, pues si bien todos somos iguales ante la ley (artículo 2-2), también pueden expedirse leyes especiales por la naturaleza de las cosas, pero no por la diferencia entre las personas (artículo 103). Esto no impide establecer tratamientos diferenciados a sectores de la población históricamente vulnerados, como la mujer, los niños, los adultos mayores (artículo 4) y los discapacitados (artículo 7), especialmente si trabajan (artículo 23).

Asimismo, se reconocen en una noción de igualdad y no discriminación formas de unión conyugal distintas del matrimonio (artículo 5), la igualdad de deberes entre padres e hijos y la igualdad entre los hijos, con independencia del estatus civil de los padres (artículo 6), el acceso universal - para todos, aunque progresivo a la seguridad social en igualdad de condiciones (artículo 10) - y la promoción de la creación de instituciones educativas para promover el mayor acceso posible a la educación como derecho (artículo 17). Igualmente, los mismos beneficios tributarios básicos para la universidad pública y privada (artículo 19), el principio de igualdad de oportunidades en el ámbito laboral (artículo 26.1), igual valor del voto como derecho de participación (artículo 31), el acceso a la función pública en condiciones de igualdad (artículo 40) y la igualdad de trato desde el Estado a las confesiones religiosas (artículo 50).

De otro lado, en el marco de nuestro régimen de economía social de mercado, las empresas públicas y privadas, nacionales y extranjeras reciben el mismo tratamiento legal (artículo 60), así como la inversión pública y privada se sujetan a las mismas condiciones (artículo 61), igualdad en materia tributaria (artículo 74), el reconocimiento de la personalidad jurídica de las comunidades campesinas y nativas históricamente soslayadas en nuestro país (artículo 88), un estatuto común de prerrogativas para los altos funcionarios del Estado (congresistas, jueces supremos y magistrados del Tribunal Constitucional, miembros del Jurado Nacional de Elecciones, el Defensor del Pueblo, los miembros del directorio del Banco Central de Reserva, el superintendente de Banca y Seguros y el Contralor General de la República), entre otras.

${ }^{4}$ Tribunal Constitucional, Exp. N. 2835 -2010-PA/TC, de 13 de diciembre de 2011, fundamento 40. 
Así, la igualdad en una interpretación sistemática de la Constitución peruana se reconoce como un derecho fundamental y como un principio constitucional, de ahí que en la jurisprudencia sea recurrente referirse al "principio-derecho de igualdad". Su reconocimiento como principio conlleva que condicione la actividad legislativa y ejecutiva, así como la aplicación e interpretación judicial del derecho objetivo (reglas) que forman parte del ordenamiento jurídico peruano.

En buena cuenta, la igualdad como principio sirve de base para la creación del derecho conforme a la igualdad constitucional, así como su interpretación y, desde luego, como sustento para colmar lagunas o reparar la discriminación normativa. Asimismo, dado su carácter de derecho fundamental, supone el derecho a no ser discriminado (prohibición de discriminación) que resulta, por ello, exigible tanto a los poderes públicos como a los particulares, dada la eficacia vertical directa y la eficacia horizontal de los derechos fundamentales en nuestro país 5 . Por ello, se ha afirmado que:

(...) la igualdad consagrada constitucionalmente, detenta la doble condición de principio y derecho fundamental. En cuanto principio, constituye el enunciado de un contenido material objetivo que, en tanto componente axiológico del fundamento del ordenamiento constitucional, vincula de modo general y se proyecta sobre todo el ordenamiento jurídico. En cuanto derecho fundamental, constituye el reconocimiento de un auténtico derecho subjetivo, esto es, la titularidad de la persona sobre un bien constitucional, la igualdad, oponible a un destinatario. Se trata del reconocimiento de un derecho a no ser discriminado por razones proscritas por la propia Constitución (origen, raza, sexo, idioma, religión, opinión, condición económica) o por otras ("motivo", "de cualquier otra índole") que, jurídicamente, resulten relevantes. En cuanto constituye un derecho fundamental, el mandato correlativo derivado de aquel, respecto a los sujetos destinatarios de este derecho (Estado y particulares), será la prohibición de discriminación. Se trata, entonces, de la configuración de una prohibición de intervención en el mandato de igualdad'.

La igualdad, al ser reconocida como un derecho fundamental, adopta la forma de un derecho subjetivo, esto es, una relación jurídica en donde se puede identificar a un sujeto titular (quien reclama se le brinde un trato igual al de otra persona con la que comparte una misma o similar situación o condición), un sujeto obligado (a quien el titular le reclama recibir el mismo tratamiento que otra persona, generalmente el Estado, pero también otros sujetos privados), y el contenido (el tratamiento que se reclama) ${ }^{7}$.

Para ponerlo en términos didácticos, podemos hacer referencia a una ley que establece que, para acceder a una pensión de viudez, la sobreviviente del causante — su viuda — solo debe

${ }^{5}$ Landa (2010), p. 40.

${ }^{6}$ Tribunal Constitucional, Exp. N. 0045-2004-PI/TC, de 29 de octubre de 2005, fundamento 20.

${ }^{7}$ Bernal (2007), p. 80. 
presentar la partida de matrimonio y la partida de defunción, que acreditan el vínculo matrimonial y la muerte del causante; en cambio a quien es viudo la ley, además de los documentos mencionados, exige la presentación de documentos que acrediten un estado de necesidad para acceder a la pensión de viudez. En dicho caso, el viudo reclamará recibir el mismo tratamiento (las mismas exigencias) que la viuda con el fin de acceder a una pensión de viudez, porque en caso contrario se le estaría brindado un tratamiento distinto a pesar de estar en la misma condición, lo cual está prohibido debido a que la razón del tratamiento discriminatorio se basaría en el sexo de la persona, uno. Además, "aunque la mayoría de estas contribuciones cubren el derecho antidiscriminatorio en su conjunto, algunas tratan un concepto específico, por ejemplo, la discriminación indirecta, el acoso y la acción positiva/cuotas, o un actor o actores específicos (organismos de igualdad, tribunales, Tribunal Europeo de Derechos Humanos)” ${ }^{8}$. Por ejemplo, en Italia, la Oficina Nacional de Anti Discriminación Racial no funciona en la práctica y no cuenta con poder alguno para asegurar la igualdad de sus ciudadanos.

En consecuencia, la igualdad como derecho ordena que todos seamos tratados iguales ante la ley, por lo que nadie debe ser discriminado por las razones prohibidas por la Constitución, aunque cabe precisar que tal mandado no prohíbe la diferenciación, siempre que se sustente en causas objetivas (no basadas en motivos prohibidos) y razonables (superen el principio de proporcionalidad) 9 . Es por esto que se considera que "los contenidos actuales atribuidos al derecho a la igualdad consisten principalmente en la obligatoriedad de un trato similar o igualdad formal y en la proscripción de la discriminación”10.

En efecto, la igualdad en tanto derecho subjetivo fundamental se entiende como una facultad que integra la esfera jurídica del ser humano, que deriva de su dignidad de la persona humana y que “(...) consiste en ser tratada igual que los demás en hechos, situaciones o acontecimiento coincidentes; por ende, deviene en el derecho subjetivo de obtener un trato igual y de evitar los privilegios y las desigualdades arbitrarias"11. Esto, como se ha señalado, no niega la diferenciación, dado que “(...) no toda desigualdad constituye necesariamente una discriminación, pues no se proscribe todo tipo de diferencia de trato en el ejercicio de los

\footnotetext{
${ }^{8}$ Havelková y Möschel (2019), p. 4.

${ }^{9}$ Díaz (2017), p. 41.

${ }^{10}$ Esparza (2018), p.18.

11 Tribunal Constitucional, Exp. N. 0018-2003-AI/TC, de 26 de abril de 2004, fundamento 2.
} 
derechos fundamentales; la igualdad solamente será vulnerada cuando el trato desigual carezca de una justificación objetiva y razonable (...)"12.

Ahora, como principio, la igualdad puede ser entendida en distintas formas: a) como una norma o principio de alcance general y por ende aplicable a una serie indeterminada de situaciones; b) como fundamento de un determinado ordenamiento jurídico o Estado ${ }^{13}$; c) como una norma que exige que algo sea realizado en la mayor medida posible considerando las circunstancias fácticas y jurídicas a favor y en contra de su aplicación ${ }^{14}$.

En la jurisprudencia constitucional se afirma que la igualdad es un principio que rige la organización y actuación de los órganos y poderes del Estado, bajo el modelo de Estado democrático y social de derecho, ya que “(...) implica un postulado o proposición con sentido y proyección normativa o deontológica que, como tal, constituye parte del núcleo del sistema constitucional de fundamento democrático"15. Un ejemplo similar en la región es "Ecuador, en condiciones casi similares de conflictividad social, mercantilización e inequidades, ha experimentado la influencia de corrientes neoconstitucionalistas, bajo cuyo prisma se adoptan políticas públicas de tutela, protección de derechos y libertades como núcleo potenciador del buen vivir"16. La igualdad es eje en torno a este debate en la región, en el que los Estados han consagrado este derecho/principio como núcleo del sistema; esto se ve reflejado en el artículo 11.2 de la Constitución de la República del Ecuador17, en la que se consagra que "el Estado adoptará medidas de acción afirmativa que promuevan la igualdad real en favor de los titulares de derechos que se encuentran en situación de desigualdad", al igual que en el artículo 2.2 de la Constitución del Perú18.

En dicho sentido, por ejemplo, en la elaboración de su tipología de sentencias atípicas ${ }^{19}$, en las que se decide de modo distinto a una mera declaración de inconstitucionalidad de una ley cuestionada, el Tribunal Constitucional ha considerado al principio de igualdad como sustento de sus sentencias aditivas.

\footnotetext{
12 Tribunal Constitucional, Exp N. 잉 2835-2010-PA/TC, de 13 de diciembre de 2011, fundamento 40.

${ }^{13}$ Landa (2008), p. 63.

${ }^{14}$ Alexy (2019), p. 79.

15 Tribunal Constitucional, Exp. N. $0018-2003-\mathrm{AI} / \mathrm{TC}$, de 26 de abril de 2004, fundamento 2.

16 Boza (2018), p. 179.

${ }^{17}$ Constitución Política de la República del Ecuador, 2008.

${ }^{18}$ Constitución Política del Perú, 1993.

${ }^{19}$ Díaz (2003), pp. 253 y ss.
} 
Las sentencias aditivas suponen que el juez constitucional detecta en su análisis alguna omisión subjetiva (sujetos no comprendidos en su ámbito de aplicación) u objetiva (situaciones de hecho no reguladas o excluidas) en la ley cuestionada, por lo que, para salvar su constitucionalidad, en virtud del principio de conservación de la ley, decide integrarla a partir del principio de igualdad incorporando a los sujetos o situaciones de hecho no reguladas (o excluidas) en el ámbito de aplicación de la norma cuestionada ${ }^{20}$. En dicho sentido, se ha señalado que:

(...) mediante las sentencias denominadas aditivas, se declara la inconstitucionalidad de una disposición o una parte de ella, en cuanto se deja de mencionar algo [en la parte en la que no prevé] que era necesario que se previera para que ella resulte conforme a la Constitución. En tal caso, no se declara la inconstitucionalidad de todo el precepto legal, sino sólo de la omisión, de manera que, tras la declaración de inconstitucionalidad, será obligatorio comprender dentro de la disposición aquello omitido ${ }^{21}$.

De lo señalado podemos señalar que, la igualdad, en la concepción que ha ido desarrollando el Tribunal Constitucional, se considera como un derecho fundamental: el derecho a no ser discriminado por un motivo prohibido por la Constitución (dimensión subjetiva), así como un principio del ordenamiento constitucional peruano (dimensión objetiva) que condiciona el accionar del Estado y de los particulares. Esta doble naturaleza con el tiempo ha ido evolucionando, a efectos de diferenciar cuándo una norma o un trato es constitucional prohibido por ser discriminatorio y cuándo una norma o un trato es permitido constitucionalmente por ser diferenciador, lo que ha dado lugar a la construcción del denominado test de igualdad para racionalizar su aplicación en los casos concretos.

\section{El concepto de la igualdad como instituto jurídico que tiene una doble naturaleza}

La igualdad puede ser conceptualizada como aquella norma que, reconociéndose como un derecho fundamental de toda persona y principio constitucional, establece una serie de mandatos dirigidos al Estado y a los sujetos privados y que prohíbe toda discriminación, aunque admite la introducción de tratamientos diferenciados entre los sujetos o sus relaciones o situaciones jurídicas, siempre que tales tratamientos estén debidamente justificados en razones objetivas y superen el test de razonabilidad y proporcionalidad.

\footnotetext{
${ }^{20}$ Landa (2011), p. 93.

${ }^{21}$ Tribunal Constitucional, Exp. N. 0010-2002-AI/TC, de 3 de enero de 2003, fundamento 30.
} 
En dicho sentido, el derecho-principio de igualdad ordena al Estado brindar el mismo tratamiento a todas las personas que reúnan las mismas condiciones (por ejemplo, viudos y viudas, hijos e hijas, inversionistas nacionales y extranjeros) o se encuentren de hecho en igual situación (por ejemplo, sujetos recluidos en establecimientos penitenciarios que han cometido el mismo delito, víctimas civiles y militares, varones, mujeres y LGTBI+ del terrorismo, etc.). Este mandato en principio se divide a su vez en dos derechos específicos: a) el derecho a ser tratado igual en la ley y en la aplicación de la ley, y b) el derecho a no ser discrimina do por ningún motivo (origen, raza, sexo, idioma, religión, opinión, condición económica o de cualquier otra índole).

¿Esto significa que todos debemos ser tratados de la misma forma siempre? Como ya se ha señalado, si bien el mandato que deriva de la Constitución es que todos debemos ser tratados en igual forma ante la ley, tal mandato admite los tratamientos diferenciados, esto es, que todos los que nos encontremos en las mismas condiciones o en la misma situación de hecho debemos ser tratados de similar forma por la ley, con lo cual, si existen diferencias relevantes, estas distinciones admiten que se puedan brindar tratamientos legislativos diferenciados. Pero si estos tratos se sustentan en algún motivo prohibido por la Constitución (origen, raza, sexo, idioma, etc.), entonces, tal tratamiento sería inválido, ya que sería calificado como discriminatorio.

Al respecto, como sustento normativo, el artículo 103 de la Constitución de $1993^{22}$ establece que pueden emitirse leyes especiales por la naturaleza de las cosas, pero no por las diferencias entre las personas.

Como ejemplo de lo indicado, tenemos que, para determinar el impuesto a la renta que una persona debe pagar al Estado, se han establecido escalas basadas en tasas que se incrementan en forma progresiva en función de los niveles de ingreso del contribuyente, en tanto no todos tenemos los mismos ingresos. Esto requiere, entonces, de un tratamiento diferenciado en función de los ingresos económicos que percibe una persona en un período previamente establecido de un año.

Finalmente, el derecho a la igualdad es un derecho de carácter relacional, en tanto "no puede existir una plena garantía de la igualdad si no se reconocen la interdependencia, indivisibilidad e interrelación de sus distintas vertientes"23. De modo tal que, la en principio la igualdad no se

${ }^{22}$ Constitución Política del Perú (1993).

${ }^{23}$ Noguera (2014), p. 303. 
lesiona de forma autónoma o en abstracto, sino en tanto y en cuanto se vincula con otro derecho — como por ejemplo el derecho a la igualdad en el trabajo-, por lo que se comparte similares características o situación con otra persona (término de comparación) que estaría siendo tratada de una forma mejor o privilegiada que al afectado, a pesar de encontrarse en la misma situación. Al respecto, el Tribunal Constitucional ha señalado que:

(...) el principio-derecho de igualdad se constituye en un presupuesto indispensable para el ejercicio de los derechos fundamentales. Posee, además, una naturaleza relacional, es decir, que funciona en la medida en que se encuentre relacionada con el resto de derechos, facultades y atribuciones constitucionales y legales. Dicho carácter relacional sólo opera vinculativamente para asegurar el goce, real, efectivo y pleno del plexo de derechos que la Constitución y las leyes reconocen y garantizan ${ }^{24}$.

Por poner un ejemplo, si del derecho de acceso a la educación se trata, la igualdad se lesiona siempre que, para acceder a un centro educativo, público o privado, se imponen requisitos o se exigen condiciones que el educando o sus padres no pueden cumplir, como que el niño tenga ciertas características físicas o que los padres estén casados. Otro caso en el que la igualdad se lesiona es el "acceso a la educación para las mujeres en países donde están excluidas o francamente limitadas a este respecto" 25 . No obstante, la educación en relación con la igualdad sí admite ciertos tratamientos diferenciados. Al respecto, los colegios de alto rendimiento financiados por el Estado solo admiten - previa evaluación - a los mejores estudiantes de los colegios públicos, quienes, al ingresar, reciben del Estado alimentación, manutención y un servicio educativo de calidad en un centro altamente especializado, que cuenta con profesores altamente capacitados e infraestructura moderna.

\section{Contenido constitucionalmente protegido del principio-derecho a la igualdad en la jurisprudencia constitucional}

En la teoría de los derechos fundamentales se ha generado una inmensa literatura en torno al denominado contenido esencial, incorporado en la Ley Fundamental de Bonn de 1949 (Alemania) y luego en la Constitución española de 1978.

Si bien la Constitución peruana no ha recogido alguna disposición específica similar a dicha figura jurídica, el Tribunal Constitucional la incorporó en un primer momento en su jurisprudencia y, luego el Código Procesal Constitucional ${ }^{26}$ la ha recogido bajo el concepto de

\footnotetext{
${ }^{24}$ Tribunal Constitucional, Exp. N. 1604-2009-PA/TC, de 22 de diciembre de 2009, fundamento 9.

${ }^{25}$ Díaz de Valdés (2019), p. 178.

${ }^{26}$ Ley N.ㅇ 28.237 (2004).
} 
"contenido constitucionalmente protegido", con la finalidad de evitar la extrapolación de los debates en torno a dicha institución (entre las denominadas teorías internas y externas, absoluta y relativa del contenido esencial). En dicho sentido, en el caso Anicama Hernández, el Tribunal Constitucional señaló que en mayor o menor medida el contenido constitucionalmente protegido de un derecho se reconduce a su contenido esencial ${ }^{27}$.

Entonces, partir del tratamiento jurisprudencial sobre el principio-derecho de igualdad, es posible identificar tres contenidos constitucionalmente protegidos:

- Igualdad formal que se divide a su vez en una igualdad ante la ley y la igualdad en la aplicación de la ley.

El primer ámbito formal de la igualdad es un mandato dirigido al legislador para que no introduzca diferenciaciones arbitrarias o carentes de justificación. Esto significa que el legislador sí puede diferenciar entre sujetos y situaciones de hecho otorgándoles un régimen jurídico diferenciado, pero tal tratamiento tendría que estar justificado en el cumplimiento de objetivos constitucionales igualmente valiosos, con lo cual un tratamiento legislativo diferenciado se convierte en arbitrario cuando carece toda justificación o, si teniéndola, está constituido por un motivo prohibido por el artículo 2.2 de la Constitución ${ }^{28}$.

Así, tenemos el caso Profa 229, donde la discusión se centraba en la compatibilidad con el principio derecho de igualdad y el derecho de acceso a la función pública en condiciones de igualdad, de la bonificación especial del 10\% sobre el puntaje obtenido para aquellos postulantes que habían llevado el programa de formación para magistrados (Profa) de la Academia de la Magistratura, en los concursos para nombramiento de jueces y fiscales y el ascenso en la carrera judicial y fiscal. En este caso, el Tribunal consideró que tal medida era discriminatoria, porque al establecer un tratamiento diferente para quienes sí llevaron el Profa (término de comparación) en relación con quienes no lo llevaron, se concluyó que el Profa podía llevarse antes o después de ingresar a la carrera judicial y fiscal, razón por la cual tal bonificación era una medida innecesaria y no permitía el concurso de todos los postulantes, para el acceso o el ascenso, en condiciones de igualdad objetiva.

27 Tribunal Constitucional, Exp. N.. 1417-2005-PA/TC, de 8 de julio de 2005, fundamento 21.

${ }^{28}$ Constitución Política del Perú (1993).

${ }^{29}$ Tribunal Constitucional, Exp. N.o 0045-2004-PI/TC, de 29 de octubre de 2005. 
Por otro lado, la igualdad en la aplicación de la ley se entiende como un mandato dirigido a la administración pública y a los jueces, en tanto órganos de aplicación de la ley y del derecho en general. Les exige que los casos con características objetivas y subjetivas que presenten similitudes relevantes similares sean resueltos de la misma forma, porque "a igual derecho, igual razón", con lo cual una solución distinta de un caso con características similares a uno ya resuelto anteriormente (término de comparación) podría ser contraria al derecho a la igualdad en la aplicación de la ley.

Por ejemplo, en el caso Consorcio Requena ${ }^{30}$, se puso en discusión la variación del criterio adoptado por una de las Salas del Tribunal de Contrataciones del Organismo Supervisor de las Contrataciones con el Estado (OSCE) respecto de los requisitos que debían cumplir el ingeniero residente de obra para que actúe como tal en proyectos de infraestructura. En el caso, la empresa demandante alegaba que la misma Sala, con la misma composición, había adoptado dos criterios distintos en dos licitaciones de obra pública en las cuales concursaba: en uno (el término de comparación), admitiendo el diploma de incorporación y el certificado de habilitación del respectivo colegio profesional como elementos idóneos para acreditar que el ingeniero sanitario es tal, y en otro no admitiendo dichos documentos. El Tribunal Constitucional consideró que sus sentencias en los dos casos eran muy similares y que no habían sido resueltas de igual forma por el mismo órgano administrativo, que empleó criterios distintos sin una debida justificación. Por esta razón, consideró que se había lesionado en dicho caso el derecho a la igualdad en la aplicación de la ley. No obstante, como sucede con el tratamiento diferenciado, puede ser que dos casos similares puedan ser resueltos de forma distinta, siempre y cuando tal variación en la forma de resolver esté debidamente justificada en la presencia de elementos subjetivos $u$ objetivos relevantes que los diferencien.

En la jurisprudencia del Tribunal Constitucional, ha establecido un test para determinar cuándo se presenta una variación arbitraria en la forma de solucionar casos iguales ${ }^{31}$ :

a) Debe existir identidad en el órgano decisor que resolvió los casos.

b) El órgano decisor debe tener una composición semejante.

c) Los supuestos de hecho involucrados deben ser sustancialmente iguales.

30 Tribunal Constitucional, Exp. N. 4293-2012-PA/TC, de 18 de marzo de 2014.

31 Tribunal Constitucional, Exp. N. 4293-2012-PA/TC, de 18 de marzo de 2014, fundamento 22. 
d) Si hay una disparidad en la respuesta jurídica.

e) No debe existir una motivación del cambio de criterio.

- Prohibición de discriminación: mandato dirigido al Estado y a los privados, que tiene una dimensión negativa, que prohíbe a toda autoridad o persona o empresa privada toda diferenciación arbitraria, carente de justificación o basada en los motivos prohibidos por la Constitución, que por ello constituirá discriminación. En dicho sentido, los casos (que involucran a niñas y mujeres, pueblos indígenas, población LGTBI+, personas con discapacidad mental y reclusos) son buena muestra de ello (sin perjuicio de algunas consideraciones de alcance general sobre el derecho a no ser discriminado que desarrollaremos en el numeral 6 siguiente).

- La igualdad material (sustancial) o dimensión positiva del principio de igualdad supone una activa intervención del Estado frente a su clásica comprensión abstencionista, con el fin de superar desigualdades estructurales para brindar mayores oportunidades de desarrollo a colectivos históricamente invisibilizados:

La vinculación positiva supone la exigencia de revertir las condiciones de desigualdad o de reponer las condiciones de igualdad de las que la realidad social pudiera estarse desvinculando, en desmedro de las aspiraciones constitucionales, a través de las acciones positivas cuyo fin sea promover real y efectivamente la igualdad sustancial entre los individuos. Ello a efectos de configurar materialmente una simetría de oportunidades para todos los seres humanos 32 .

De ahí que, por ejemplo, se han ido desarrollando desde el Estado las denominadas medidas de discriminación inversa o discriminación positiva, porque desde el Estado se brindan ciertas "ventajas" a determinados sectores de la población: becas de estudios para jóvenes de bajos recursos, cuotas de empleo para discapacitados, acceso al seguro integral de salud para personas por debajo de la línea de pobreza y a migrantes forzados por razones humanitarias, el programa Juntos para adultos mayores en situación de pobreza extrema, cuotas electorales para jóvenes y mujeres, entre otras medidas que buscan mejorar las condiciones de vida de la población y posibilitarles mejores oportunidades para tener una vida digna o lograr su propio desarrollo personal.

32 Tribunal Constitucional, Exp. N. 0018-2003-AI/TC, de 26 de abril de 2004, fundamento 2. 
Pero estas medidas no solo tienen este cariz personalista, sino que también se traducen, en materia económica, en ciertos incentivos, como son las exoneraciones tributarias para la región de la Amazonia, los contratos de estabilidad tributaria contra millonarios compromisos de inversión, entre otros beneficios que buscan promover la inversión privada y los grandes proyectos de explotación e infraestructura en el país.

\section{Alcances del principio-derecho de igualdad en la jurisprudencia del Tribunal Constitucional}

El derecho-principio a la igualdad tiene un alcance general, dado que, como principio, rige en todo tipo de relaciones y situaciones jurídicas públicas y privadas.

De ahí que, por ejemplo, los órganos judiciales no pueden modificar de forma arbitraria sus decisiones previas y deben estar sujetos a los precedentes que se dicten, salvo que sustenten el apartamiento del precedente judicial o administrativo.

En dicho sentido, cuando una persona invoca la lesión a su derecho a la igualdad en la aplicación de la ley, siempre debe ofrecer un término de comparación, es decir, otro caso u otro sujeto que sirva a quien debe aplicar el derecho como medida de comparación respecto del tratamiento que el solicitante exige recibir. En la jurisprudencia del Tribunal se han señalado dos características que debe reunir el término de comparación ${ }^{33}$ :

- En primer lugar, debe tratarse de una situación o relación jurídica lícita, puesto que no se podría ofrecer como término de comparación un hecho ilícito o prohibido por el derecho.

- En segundo lugar, el término de comparación debe presentar propiedades que, fáctica y jurídicamente, sean sustancialmente análogas, no idénticas, pero sí similares, tanto por las condiciones que reúnen los sujetos que se comparan como las situaciones de hecho y de derecho en las que están inmersos. Si esto no fuera posible, el término de comparación es inválido.

Un claro ejemplo de un término de comparación válido es el del caso Consorcio Requena ${ }^{34}$, donde se había ofrecido como término de comparación otro caso en el que el demandante era la

33 Tribunal Constitucional, Exp. N.. 00015-2010-PI/TC, de 11 de setiembre de 2012, fundamento 9.

34 Tribunal Constitucional, Exp. N. $4293-2012-\mathrm{PA} / T C$, de 18 de marzo de 2014. 
misma empresa y la cuestión que se discutía era la misma: la acreditación del profesional de ingeniería sanitaria a través de documentos distintos al título profesional.

En el caso del principio de igualdad ante la ley, el Tribunal ha tenido una evolución en su jurisprudencia; de modo tal que, en las primeras sentencias del período que se investiga, el Tribunal señalaba que un tratamiento legislativo era contrario al principio de igualdad, cuando el tratamiento diferenciado carecía de una justificación objetiva y razonable:

(...) la igualdad se configura como un derecho fundamental de la persona a no sufrir discriminación jurídica alguna; esto es, a no ser tratada de manera dispar respecto a quienes se encuentren en una misma situación, salvo que exista una justificación objetiva y razonable de esa desemejanza de trato (...) a la base objetiva y razonable de la diferenciación debe añadirse la racionalidad. Ésta debe ser entendida como la necesidad de acreditar la adecuación del medio empleado por la ley con los fines perseguidos por ella. Esto implica la existencia de una conexión o vínculo eficaz entre el trato diferenciado que se legaliza, el supuesto de hecho que lo justifica y la finalidad que se pretende alcanzar 35 .

Luego de esta primera línea jurisprudencial, el Tribunal experimentó un cambio con la incorporación del principio de proporcionalidad, dando origen al denominado test de igualdad sobre el cual se volverá en el numeral 7 del presente trabajo.

Finalmente, la igualdad también rige en el ámbito de las relaciones privadas, así, por ejemplo, en el ámbito laboral ha tenido un desarrollo interesante, en la medida que, por ejemplo, despidos basados en el embarazo de una mujer han sido declarados nulos por discriminatorios ${ }^{36}$.

De igual manera, en las relaciones de consumo, se han adoptado medidas afirmativas, como cuando se permite el ingreso a los supermercados a los invidentes con sus perros guías o lazarillos ${ }^{37}$, casos que serán analizados en capítulos específicos en el presente libro.

\section{El derecho a no ser discriminado a partir de la jurisprudencia constitucional}

El derecho a no ser discriminado o prohibición de discriminación exige abordar algunos tipos de discriminación que se han ido desarrollado en los instrumentos internacionales, la doctrina y la jurisprudencia constitucional. En dicho sentido, seguiremos de cerca las distinciones desarrolladas por Salomés8, empleando algunos ejemplos de la propia jurisprudencia

\footnotetext{
35 Tribunal Constitucional, Exp. N. $00261-2003-\mathrm{AA} / \mathrm{TC}$, de 26 de marzo de 2003, fundamento 7 y 9.

36 Tribunal Constitucional, Exp. N. - 5652-2007-PA/TC, de 6 de noviembre de 2008, fundamento 47-56.

37 Tribunal Constitucional, Exp. N. 2437-2013-PA/TC, de 16 de abril de 2014, fundamento 20.

38 Salomé (2017), pp. 261-285.
} 
constitucional. Cabe añadir que todos estos tipos de discriminación están prohibidos; no obstante, el grado de eficacia de su remoción depende de las medidas que adopte el Estado, que no se limitan a decisiones judiciales, sino que requieren normas (legales y administrativas) y, especialmente, la transformación de prácticas de conducta muy arraigadas en nuestra sociedad, profundamente desigual.

\subsection{DISCRIMINACIÓN DIRECTA E INDIRECTA}

Como punto de inicio, no debemos perder de vista que, en virtud del principio-derecho a la igualdad y a la no discriminación, se debe tratar igual a los que están en una misma situación jurídica o fáctica, y de modo distinto a quienes se encuentren en situaciones diferentes, por lo que esta aproximación conceptual admite la diferenciación. Sin embargo, cuando esta se sustenta en un motivo prohibido expresamente por la Constitución (origen, raza, sexo, origen, idioma, religión, opinión o condición económica) estamos frente a una discriminación directa. Esto ha sucedido en nuestra experiencia cuando en el caso de las mujeres embarazadas estas son separadas de su centro laboral ${ }^{39}$ o son separadas de su proceso formativo en la carrera militar ${ }^{40}$. Al respecto, el Tribunal ha recogido el siguiente concepto de discriminación directa:

La discriminación en el trabajo puede ser directa o indirecta. Es directa cuando las normas jurídicas, las políticas y los actos del empleador, excluyen, desfavorecen o dan preferencia explícitamente a ciertos trabajadores atendiendo a características como la opinión política, el estado civil, el sexo, la nacionalidad, el color de la piel o la orientación sexual, entre otros motivos, sin tomar en cuenta sus cualificaciones y experiencia laboral. Por ejemplo, los anuncios de ofertas de empleo en los que se excluye a los aspirantes mayores de cierta edad, o de determinado color de piel o complexión física, es una forma de discriminación directa ${ }^{41}$.

En cambio, la discriminación es indirecta cuando se emplea un motivo aparentemente neutral (no prohibido constitucionalmente), pero que por los resultados de la propia situación se advierte un resultado perjudicial por su aplicación. En dicho sentido, en la misma sentencia antes indicada el Tribunal Constitucional señaló que:

(...) la discriminación es indirecta cuando ciertas normas jurídicas, políticas y actos del empleador de carácter aparentemente imparcial o neutro tienen efectos desproporcionadamente perjudiciales en gran número de integrantes de un colectivo determinado, sin justificación alguna e independientemente de que éstos cumplan o no los requisitos exigidos para ocupar el puesto de trabajo de que se trate, pues la aplicación de una misma condición, un mismo trato o una misma exigencia no se les exige a todos por igual. Por ejemplo, el supeditar la obtención de un puesto de trabajo al dominio de un idioma en particular cuando la capacidad lingüística no es requisito

\footnotetext{
${ }^{39}$ Tribunal Constitucional, Exp. N. $5652-2007-P A / T C$, de 6 de noviembre de 2008.

40 Tribunal Constitucional, Exp. N. $01423-2013-\mathrm{PA} / \mathrm{TC}$, de 9 de diciembre de 2015.

41 Tribunal Constitucional, Exp. N. 5652-2007-PA/TC, de 6 de noviembre de 2008, fundamento 44 .
} 
indispensable para su desempeño es una forma de discriminación indirecta por razón de la nacionalidad o la etnia de origen.

También puede haber discriminación indirecta cuando se dispensa un trato diferenciado a categorías específicas de trabajadores, traducida en menores prestaciones sociales o remuneraciones, siempre que éste no se realice sobre bases objetivas y razonables ${ }^{42}$.

Como ejemplos de discriminación indirecta se suele citar, por ejemplo, el establecimiento de una talla determinada para el acceso a una escuela militar, pues dependiendo del contexto social y cultural, establecer una talla determinada puede resultar perjudicial para un determinado grupo social, como las mujeres. De igual manera, una política remunerativa que haga distinciones entre cargos sin considerar adecuadamente el trabajo que se desarrolla (las funciones o actividades laborales) puede resultar discriminatoria cuando a pesar de que se establecen funciones distintas entre diversos grupos o cargos laborales, en la práctica terminan haciendo el mismo tipo de labor o con la misma carga de trabajo.

\subsection{DISCRIMINACIÓN POR INDIFERENCIACIÓN}

Este tipo de discriminación se presenta cuando se invisibilizan las diferencias entre sujetos, teniendo como resultado que reciban un mismo tratamiento (legal, administrativo, judicial o particular) cuando, en los hechos, deben recibir un tratamiento diferenciado.

En la jurisprudencia constitucional tenemos el caso de la prohibición de ingreso a un supermercado con perro guía para personas invidentes ${ }^{43}$. El Tribunal hace referencia a que el deber de protección estatal no se limita a las atenciones sanitarias sino que se extiende a la adopción de ajustes razonables - es decir, adecuados y necesarios y que no supongan una carga indebida o excesiva-, que se requieren para las exclusiones de las que históricamente han sido víctimas ${ }^{44}$, las que se sustentan en que su exclusión de diversos procesos sociales (familia, educación, trabajo, etc.) se deben al entorno o ambiente social en el que se ven forzados a interactuar ${ }^{45}$. Así, los ambientes y el entorno se han diseñado teniendo como paradigma a una persona sin discapacidad 46 .

En el caso en cuestión, el Tribunal consideró que era contrario al principio de igualdad y no discriminación de las personas con discapacidad visual que no se les permitiera el ingreso con perros guías a un supermercado, porque aun cuando este establecimiento disponga de asistencia

\footnotetext{
${ }^{42}$ Tribunal Constitucional, Exp. N. 5652-2007-PA/TC, de 6 de noviembre de 2008, fundamento 45.

43 Tribunal Constitucional, Exp. N. 2437-2013-PA/TC, de 16 de abril de 2014.

${ }_{44}$ Tribunal Constitucional, Exp. N. $2437-2013-P A / T C$, de 16 de abril de 2014, fundamento 7.

45 Tribunal Constitucional, Exp. N. 2437-2013-PA/TC, de 16 de abril de 2014, fundamento 8.

46 Tribunal Constitucional, Exp. N. 2437-2013-PA/TC, de 16 de abril de 2014, fundamento 9.
} 
humana para personas discapacitadas —incluyendo las invidentes ${ }^{47}$, señala el Tribunal一, la discriminación se presenta entre dos grupos de sujetos: personas con discapacidades distintas de las visuales y personas con discapacidad visual, atendiendo a que son grupos distintos, negarles el ajuste razonable (uso de perros guías) supone una discriminación por indiferenciación ${ }^{48}$, pues la discapacidad visual no supone una incapacidad para quienes la padecen, dado que no los incapacita para valerse por sí mismos ${ }^{49}$.

De ahí que el uso de perros guía — ajuste razonable - para personas con discapacidad visual les permite desarrollarse con autonomía y con el máximo de independencia posible en dichos establecimientos $^{50}$. Lo contrario supone una lesión al derecho al libre desarrollo de la personalidad, así como el derecho a gozar de un ambiente adecuado para su desenvolvimiento libre y autónomo ${ }^{51}$.

\subsection{DISCRIMINACIÓN INTERSECCIONAL O MÚLTIPLE}

La discriminación es interseccional o múltiple cuando desde el Estado o los particulares se desarrollan ciertas prácticas o tratamientos basados en más de un motivo discriminatorio, afectando con ello a una persona en particular o a un colectivo específico.

$\mathrm{Al}$ respecto - por paradójico que resulte-, un ejemplo claro es el de la segunda sentencia del propio Tribunal Constitucional sobre la píldora del día siguiente o AOE $2^{52}$. En el fallo solo se prohíbe que el Ministerio de Salud distribuya de forma gratuita la píldora del día siguiente; no obstante, no se establece tal prohibición para su venta en farmacias privadas y establecimientos comerciales (la argumentación se basa en nociones economicistas, cuestionable desde luego) 53 .

Dicha sentencia generó una discriminación múltiple por las siguientes razones: las destinatarias de la anticoncepción oral de emergencia son las mujeres, con lo cual la decisión del Tribunal introduce un criterio económico que diferencia entre quienes tienen el poder adquisitivo para adquirirla en farmacias privadas pagando su precio, y quienes no pueden acceder a la píldora del día siguiente de forma gratuita en el sistema público de salud.

\footnotetext{
47 Tribunal Constitucional, Exp. N. $2437-2013-\mathrm{PA} / \mathrm{TC}$, de 16 de abril de 2014, fundamento 28.

48 Tribunal Constitucional, Exp. N. - 2437-2013-PA/TC, de 16 de abril de 2014, fundamentos 31 у 32.

${ }^{49}$ Tribunal Constitucional, Exp. N. 2437-2013-PA/TC, de 16 de abril de 2014, fundamento 36.

${ }^{50}$ Tribunal Constitucional, Exp. N. $-2437-2013-\mathrm{PA} / \mathrm{TC}$, de 16 de abril de 2014, fundamento 35 y 36.

51 Tribunal Constitucional, Exp. N. 2437-2013-PA/TC, de 16 de abril de 2014, fundamento 40.

52 Tribunal Constitucional, Exp. N. 일 2005-2009-PA/TC, 16 de octubre de 2009.

53 Tribunal Constitucional, Exp. N. 2005-2009-PA/TC, 16 de octubre de 2009, fundamentos 55 y 62.
} 
En la eventualidad, por ejemplo, de embarazos no deseados (con independencia de sus razones y de si estas conllevan la violación de su consentimiento), las mujeres en situación de pobreza o pobreza extrema que, además, puedan haber sido víctimas de violencia sexual no podrán acceder a este método anticonceptivo, lo que origina otros problemas asociados al embarazo no deseado que podría generarles otras limitaciones, como la frustración de su proyecto de vida o teniendo una incidencia en su incorporación al mercado de trabajo (debiendo optar por el mercado informal). Todo ello no hace sino generar que en el grupo de mujeres que no pueden adquirir el anticonceptivo oral de emergencia concurra más de un motivo discriminatorio.

\subsection{DISCRIMINACIÓN ESTRUCTURAL O SISTÉMICA}

Finalmente, la discriminación estructural o sistemática conlleva la existencia de situaciones de desigualdad social, de subordinación o dominación que perjudican a grupos determinados dentro de la sociedad, a las que se puede identificar con aquellas que se encuentran en situación de vulnerabilidad. Estas situaciones pueden tener orígenes históricos, culturales, políticos, económicos y además jurídicos, pues resulta que la propia institucionalidad estatal puede terminar validando o acentuando tal discriminación. De ahí que se la califique como estructural o sistémica, pues no se trata de una acción más o menos individualizable, sino de un conjunto de acciones o prácticas arraigadas en la propia sociedad y en la institucionalidad estatal. Un ejemplo de esta discriminación estructural y sistemática es la discriminación por género. "Una sentencia histórica emitida recientemente por el ECHR refiere a la prohibición de la discriminación por razón de sexo y a la obligación de los Estados de proteger a las mujeres de la violencia doméstica; es la primera vez que el Tribunal sostiene que la violencia de género es una forma de discriminación según el Convenio Europeo"54, lo que también se ve en nuestro país en tanto es una sociedad fuertemente influida por la cultura dominante y valores religiosos que permiten discriminar a este grupo de manera sistemática.

En dicho sentido pueden mencionarse algunos ejemplos: a) los migrantes venezolanos que los últimos años han llegado al país, quienes se enfrentan situaciones de abuso laboral, xenofobia e incluso persecución de los agentes del Estado (autoridades migratorias, policiales y municipales) e incluso un estigma social — promovido por ciertos sectores- de que ellos son los que causan violencia o vienen a quitarles el trabajo a los peruanos; b) los miembros de la

${ }^{54}$ Danisi (2011), pp. 798-799. 
población LGTBI+, que además de la discriminación, también son sujetos de estereotipos que incluso son acentuados por programas "humorísticos", además de padecer distintos tipos de violencia; c) las mujeres y niñas, que desde hace años, por su sola condición, padecen distintos tipos de discriminación y abusos, incluida la violencia estructural, ya que esta no proviene solo de su entorno social cercano sino también de la indiferencia de las autoridades estatales que no adoptan las medidas que incluso están legalmente previstas para protegerlas; d) las personas con discapacidad, que tienen que sortear serios obstáculos para insertarse en el mercado laboral, además de no recibir los ajustes razonables para desarrollarse con relativa autonomía en el entorno social; e) los adultos mayores, que por parte de sus propias familias son sujetos a violencia, estereotipos de inutilidad y dependencia, además de tener una salud vulnerable, por su misma edad; f) los pueblos indígenas, quienes durante cientos de años han vivido y siguen viviendo excluidos de la moderna sociedad, buscando el reconocimiento de su autonomía por la institucionalidad estatal; g) los reclusos, quienes están cumpliendo una condena por vulnerar bienes jurídicos, ven afectados — además de su libertad- otros derechos, como su salud, integridad y vida (incluso) por distintos condicionantes: hacinamiento, insuficiencia de infraestructura sanitaria dentro de las cárceles, violencia y corrupción; entre otros grupos vulnerables. Cabe añadir que en el contexto de la pandemia por la Covid-19 todos estos grupos vulnerables han visto acentuada su precaria situación, en perjuicio de la protección de sus derechos fundamentales más básicos, como la salud, integridad y vida.

Sobre estos grupos que padecen discriminación estructural, el Tribunal Constitucional ha reconocido esto en dos casos específicos referidos a mujeres y adultos mayores. En dicho sentido, sobre las mujeres se ha señalado que:

12. La situación de desigualdad que afrontan las mujeres en las sociedades modernas es un problema estructural. En consecuencia, se requiere que el derecho a la igualdad sea ampliado. No basta entender igualdad como no discriminación, sino también como reconocimiento de grupos desventajados. Ello permite incorporar datos históricos y sociales que den cuenta de fenómenos de sometimiento y exclusión sistemática a la que se encuentran amplios sectores de la sociedad, en este caso en particular el de las mujeres. En esa línea, se trata de desmantelar la estructura social que sostiene una serie de prácticas que se acumulan sobre las mujeres "desaventajadas"55.

55 Tribunal Constitucional, Exp. N. 1272-2017-PA/TC, de 5 de marzo de 2019, fundamento 12. 
13. En esta línea de pensamiento, el derecho a la igualdad definida en estos términos de igualdad formal o material no es suficiente para dar cuenta de estos problemas estructurales. En ese sentido, aquellas personas que padecen los efectos de esa discriminación no pueden salir de esa situación en forma individual y por sus propios medios, sino que se requieren medidas de acción positiva reparadoras o transformadoras para lograr igualdad real de oportunidades para el ejercicio de los derechos. En consecuencia, para tratar problemas como los aquí anotados surge la necesidad de ampliar la noción de igualdad 56 .

14. Precisamente, asumir la noción de igualdad como reconocimiento y no sometimiento permite abarcar las injusticias conocidas como culturales, aquellas arraigadas en los modelos de la representación, interpretación y comunicación. Ello se extiende, por ejemplo, para los grupos raciales, que están marcados como distintos e inferiores, y a las mujeres, quienes son trivializadas, cosificadas sexualmente y a las cuales se les falta al respeto de formas diferentes ${ }^{57}$.

15. Finalmente, la igualdad como redistribución y reconocimiento afirma que la igualdad debe ser construida en cada caso concreto, con la participación de todos los implicados en la situación de desigualdad. En consecuencia, la interpretación de la igualdad debe adecuarse a la segmentación social que el paradigma predominante ha producidos. Así entendido, el Tribunal Constitucional no puede hacer caso omiso a la vulneración de los derechos fundamentales de las mujeres ${ }^{58}$.

Finalmente, en lo que a los adultos mayores se refiere, el Tribunal en un caso vinculado con la protección del derecho a la identidad de los adultos mayores ${ }^{59}$ que, aun cuando la demandante ya había fallecido (por un accidente de tránsito) para cuando se emitió la sentencia, señaló que el Reniec, considerando la edad avanzada de la demandante (76 años), debió tener un especial cuidado al resolver los cuestionamientos dirigidos a la demandante por una presunta falsa identidad, teniendo presente que en el propio expediente administrativo existían documentos que acreditaban su verdadera identidad 60 .

En la sentencia, el Tribunal señaló, como doctrina jurisprudencial, que los adultos mayores se encuentran en una especial situación de vulnerabilidad (por estereotipos, pérdida progresiva

\footnotetext{
${ }^{56}$ Tribunal Constitucional, Exp. N. 1272-2017-PA/TC, de 5 de marzo de 2019, fundamento 13.

57 Tribunal Constitucional, Exp. N. $1272-2017-P A / T C$, de 5 de marzo de 2019, fundamento 14.

58 Tribunal Constitucional, Exp. N. $-1272-2017-\mathrm{PA} / \mathrm{TC}$, de 5 de marzo de 2019, fundamento 15.

59 Tribunal Constitucional, Exp. N. 2834-2013-PHC/TC, de 25 de enero de 2017.

${ }^{60}$ Tribunal Constitucional, Exp. N.ㅇ 2834-2013-PHC/TC, de 25 de enero de 2017, fundamento 42.
} 
de autonomía y riesgos en su salud asociados a la edad) ${ }^{61}$, lo que puede ir acompañado de otros factores de discriminación interseccional o múltiple, esto es, la concurrencia de otras circunstancias o factores (como el género, la condición económica, la pertenencia a una minoría étnica) que agravan la vulnerabilidad de la persona adulta mayor62. Es así como "subyace la idea de que los derechos tienen una finalidad de protección de la parte más débil de una relación"63. Esta idea tiene origen en la Edad Contemporánea y se sustenta en que las relaciones entre individuos son desigualitarias, tal y como vemos en el presente caso.

Por ello, el Estado - y especialmente la Reniec - deben otorgar un tratamiento preferente, procedimientos flexibles, e incluso de oficio, para asegurar el derecho a la identidad de los adultos mayores que por su propia condición se encuentran en situaciones de vulnerabilidad, más aún cuando el DNI es empleado para el goce o ejercicio de otros derechos como la pensión, la salud y la libertad personal64.

En consecuencia, el Estado y sus instituciones debe adoptar acciones positivas de toda índole para prevenir cualquier acto de discriminación en contra de las personas adultas mayores, lo que incluye la sensibilización de sus servidores, funcionarios y de la sociedad en general acerca del trato preferente y especial que deben recibir65.

Finalmente, el Tribunal estableció como mandatos adicionales: i) la implementación de mecanismos o procedimientos especiales que faciliten el reconocimiento de la identidad de determinadas personas en condiciones de vulnerabilidad (adultos mayores) que permita tutelar su derecho a la identidad de acuerdo con los criterios antes establecidos, y ii) identificar aquellos procedimientos o prácticas de dicha entidad que necesitan ser superadas, revertidas, modernizadas o simplificadas, atendiendo a lo desarrollado en la sentencia de autos ${ }^{66}$.

Si bien en dicha sentencia se emplea el concepto de discriminación interseccional, consideramos que, dado lo que finalmente se resuelve (disposiciones para que se modifiquen prácticas estatales institucionalizadas), en realidad el Tribunal identificó un caso de discriminación estructural.

${ }^{61}$ Tribunal Constitucional, Exp. N. 2834-2013-PHC/TC, de 25 de enero de 2017, fundamento 20.

62 Tribunal Constitucional, Exp. N. - 2834-2013-PHC/TC, de 25 de enero de 2017, fundamentos 21 y 22.

${ }^{63}$ Díaz (2015), p. 18.

64 Tribunal Constitucional, Exp. N.. 2834-2013-PHC/TC, de 25 de enero de 2017, fundamentos 33 y 35 .

65 Tribunal Constitucional, Exp. N. - 2834-2013-PHC/TC, de 25 de enero de 2017, fundamento 41.

66 Tribunal Constitucional, Exp. N.ㅇ 2834-2013-PHC/TC, de 25 de enero de 2017, fundamento 43. 
Por último, cabe señalar que la reparación de esta forma de discriminación es sumamente compleja y amerita, además de una solución concreta para la persona que formula la demanda en tanto sea lesionada en sus derechos, una respuesta integral y proporcional al problema identificado que se quiere resolver, en relación con las causas que lo motivan. De ahí que, en estos casos, el Tribunal Constitucional haya empleado la técnica del estado de cosas inconstitucionales.

\section{Mecanismos de tutela procesal de la igualdad y la no discriminación}

La igualdad y la no discriminación, en tanto derecho fundamental (dimensión subjetiva) y principio constitucional (dimensión objetiva), se tutelan, en principio, a través de los procesos administrativos, judiciales $\mathrm{y}$, de forma reforzada y subsidiaria, mediante los procesos constitucionales previstos en el artículo 200 de la Constitución ${ }^{67}$ :

- La prohibición de discriminación, en primer lugar, puede ser tutelada a través de mecanismos administrativos, como lo evidencian los conflictos ocurridos al interior de las relaciones de consumo, en donde los proveedores de bienes o servicios han actuado de forma discriminatoria impidiendo que algunos sectores de la población puedan acceder a los servicios que prestan o prohibiendo ciertas conductas a un grupo de personas (parejas homosexuales) o sector de la población y no a otros (parejas heterosexuales), a pesar de que ambos realicen el mismo tipo de conducta (muestras de afecto). Esta protección administrativa, en caso de ser deficiente puede controlarse a través de los procesos judiciales, ordinarios o constitucionales, dependiendo del cumplimiento de sus respectivos presupuestos procesales.

- El principio-derecho a la igualdad también puede ser protegido a través de los procesos judiciales ordinarios que, según ha señalado el Tribunal Constitucional, siguiendo a un profesor español68, constituyen la primera valla de defensa de los derechos frente a la arbitrariedad de los poderes públicos y de los privados ${ }^{69}$, pues el Código Procesal Constitucional ${ }^{70}$ ha recogido como característica del amparo su subsidiariedad. Los procesos ordinarios culminan en la Corte Suprema de Justicia de la República y

\footnotetext{
${ }^{67}$ Constitución Política del Perú (1993).

${ }^{68}$ López (2001).

${ }^{69}$ Tribunal Constitucional, Exp. N. 0 0206-2005-PI/TC, de 28 de noviembre de 2005, fundamento 5 .

${ }^{70}$ Ley N.․ 28.237 (2004).
} 
eventualmente, de considerar que aún no se ha reparado la discriminación demandada, el afectado podría cuestionar lo resuelto por los jueces ordinarios ante los procesos constitucionales, básicamente el amparo y el hábeas corpus contra resoluciones judiciales (artículo 4 del Código Procesal Constitucional).

- La igualdad como derecho y como principio recibe una protección reforzada a través de los procesos constitucionales, básicamente el proceso de amparo y el hábeas corpus (cuando los sentenciados por terrorismo, por ejemplo, reclaman beneficios penitenciarios que no se le otorgan por mandato legal, como la visita íntima). Estos procesos se inician en el Poder Judicial y pueden terminar en el Tribunal Constitucional, quien resuelve como última y definitiva instancia.

Así también, desde una perspectiva más objetiva, como principio, la igualdad recibe protección reforzada mediante el proceso de inconstitucionalidad cuando se cuestionan tratamientos legislativos que pueden ser calificados como discriminatorios. El Tribunal Constitucional es el único competente para resolver este proceso de control normativo.

\section{Límites a la igualdad partir del test de proporcionalidad}

El principio-derecho de igualdad - como todo derecho- tiene límites, dado que no es absoluto, y tales límites se evalúan a partir del denominado test de igualdad, elaborado a partir de la integración de la igualdad y el principio de proporcionalidad71.

Este test tiene su versión más desarrollada en la sentencia del caso Profa 272. En esta se establecieron seis pasos para determinar si un tratamiento diferenciado resulta contrario o no al principio-derecho de igualdad. Cabe añadir que, si alguno de estos pasos no se supera, la medida analizada debería ser considerada como inconstitucional. Los pasos del test son los siguientes:

- Determinación de la intervención en la prohibición de discriminación.

- Determinación de la intensidad de la intervención en la igualdad.

\footnotetext{
${ }^{71}$ Bernal (2005), pp. 274 y ss.

72 Tribunal Constitucional, Exp. N. 0045-2004-PI/TC, de 29 de octubre de 2005, fundamento 33; asimismo, Bernal (2006).
} 
- Determinación del fin y objetivo del tratamiento diferenciado.

- Análisis de idoneidad.

- Análisis de necesidad.

- Análisis de proporcionalidad en sentido estricto.

Siguiendo con el caso citado, en él se determinó lo siguiente:

a) La intervención en la prohibición de discriminación supone determinar cuál es el tratamiento diferente entre dos destinatarios de una norma; en este caso, la bonificación del Profa en los concursos de acceso a la carrera judicial y fiscal estableció un tratamiento favorable a quienes lo habían llevado en detrimento de quienes no lo habían cursado, con lo cual se tenía dos grupos de sujetos que, estando en la misma situación, recibían un tratamiento distinto de la ley: concursantes con Profa y concursantes sin Profa. Los primeros recibían la bonificación especial en el puntaje, en tanto que los segundos no ${ }^{73}$.

b) La intensidad de dicha intervención, a decir del Tribunal, se establece a través de una escala de grados: b.1) intervención grave en la prohibición de discriminación cuando la diferenciación legislativa se sustenta en un motivo prohibido por la Constitución y lesiona derechos fundamentales; b.2) intervención grado intermedio en la prohibición de discriminación cuando la diferenciación se basa en un motivo prohibido por la Constitución y lesiona un derecho de origen legal o interés legítimo; b.3) intervención leve en la prohibición de discriminación cuando la diferenciación se sustenta en motivos distintos de los prohibidos por la Constitución y lesiona un derecho legal o interés legítimo $^{74}$.

En el caso en concreto, el Tribunal consideró que la intensidad de la intervención era grave; no obstante, no sustentó en qué motivo prohibido por la Constitución se sustentaba la diferenciación, aunque sí justificó qué derecho fundamental se lesionaba. Por ello, consideramos que la diferenciación se sustentaba en la condición económica, dado que solo aquellos postulantes que podían sufragar los costos del mencionado Profa podían tener la bonificación (en los años previos al caso, el Profa tenía un costo elevado para el nivel de ingresos per cápita),

73 Tribunal Constitucional, Exp. N. ㅇ 0045-2004-PI/TC, de 29 de octubre de 2005, fundamento 34.

${ }^{74}$ Tribunal Constitucional, Exp. N.o 0045-2004-PI/TC, de 29 de octubre de 2005, fundamento 35. 
y el derecho afectado, como lo desarrolló el Tribunal, era el derecho de acceso a la carrera judicial y fiscal en igualdad de condiciones (derivado del derecho de acceso a la función pública en condiciones de igualdad).

c) A decir del Tribunal, la finalidad de una medida legislativa que interviene en la prohibición de discriminación es realizar un principio o valor constitucional, en tanto que el objetivo viene a ser el estado de cosas que se quiere lograr con la medida legislativa cuestionada. En el caso que es materia de ejemplo, se concluyó que la finalidad era contar con una magistratura idónea para brindar un adecuado servicio de justicia, que en último término se sustentaba en el derecho a la tutela jurisdiccional, en tanto que el objetivo era tener magistrados mejor capacitados para el desempeño de su función ${ }^{75}$.

d) En cuanto a la idoneidad, se debe determinar si el medio empleado es idóneo o adecuado para lograr la finalidad y el objetivo propuesto (relación medio-fin) como justificación de la medida diferenciadora; en el caso de la bonificación del Profa, sí cumplía con la idoneidad, dado que los cursos del Profa reforzaban los conocimientos jurídicos de jueces y fiscales, con lo cual se podía entender que postulantes mejor capacitados, en caso de ser seleccionados, podrían desarrollar su labor de mejor manera, lo que redundaría en mejores niveles de satisfacción del derecho a la tutela jurisdiccional de los ciudadanos ${ }^{76}$.

e) En cuanto al análisis de necesidad, se debe determinar si no existen medidas alternativas igual de idóneas para lograr el fin propuesto y que justifiquen la medida legislativa que interviene en la prohibición de discriminación, pero que lesionen menos el derecho intervenido. Esto presupone, a decir del Tribunal, que debe existir una medida alternativa que, cuando menos, debe ser igual de idónea o más idónea que la medida analizada y que además lesione en menor intensidad la prohibición de discriminación ${ }^{77}$.

A consideración del Tribunal, en el caso de la bonificación del Profa sí existía una medida alternativa a la que se analizaba. En su diseño, el Profa se constituía en una bonificación porque así estaba contemplado en la ley, con lo cual los postulantes que podían asumir sus costos lo

\footnotetext{
75 Tribunal Constitucional, Exp. N. 0045-2004-PI/TC, de 29 de octubre de 2005, fundamento 37.

76 Tribunal Constitucional, Exp. N. $0045-2004-\mathrm{PI} / \mathrm{TC}$, de 29 de octubre de 2005, fundamento 38.

77 Tribunal Constitucional, Exp. N.o 0045-2004-PI/TC, de 29 de octubre de 2005, fundamento 39.
} 
llevaban antes de postular para que, cuando se involucrasen en el concurso, pudieran acceder a la bonificación.

Para no quebrar la igualdad de oportunidades para el acceso a la magistratura, el Tribunal consideró que el Profa podría exigirse a abogados que ya hubiesen ingresado a la magistratura, con lo cual el objetivo perseguido con la medida legislativa que interviene en la prohibición de discriminación - jueces y fiscales mejor capacitados - se podía obtener cuando los postulantes ya hubiesen ingresado a la carrera fiscal o judicial. Con ello, se evitaba crear una diferenciación arbitraria (postulantes con Profa y postulantes sin Profa).

Al no haber superado el examen de necesidad, el Tribunal concluyó que la medida analizada era inconstitucional por ser innecesaria, al existir medidas alternativas igual de idóneas que cumplen el fin y que no intervienen en la prohibición de discriminación.

f) Finalmente, el test de ponderación o proporcionalidad en sentido estricto implica aplicar la denominada ley de la ponderación con el fin de determinar si al grado de intervención en la prohibición de discriminación se encuentra debidamente justificado por el grado de realización del principio o derecho que se le opone en el caso. Según la fórmula estándar: cuanto más intensa es la intervención o realización de un principio, tanto más importante debe ser la realización intervención del otro principio en juego. Para la aplicación de esta ley de la ponderación se determinan los grados de realización e intervención de los derechos o principios en juego, así como su peso abstracto y la seguridad de las premisas fácticas del caso. Todo ello, ordenado en una fórmula que permite racionalizar el análisis y efectuar una presentación ordenada de la valoración de las distintas variables en juego ${ }^{78}$.

Por último, un precedente constitucional interesante es aquel en que se cuestiona el accionar de un privado, en la medida en que se emplea este esquema argumentativo para determinar si un supuesto de discriminación por indiferenciación supera el test de la igualdad: el referido a la prohibición de que las personas invidentes ingresen con un perro guía a un supermercado en $\operatorname{Lima}^{79}$.

78 Tribunal Constitucional, Exp. N. 0045-2004-PI/TC, de 29 de octubre de 2005, fundamento 40.

${ }^{79}$ Tribunal Constitucional, Exp. N.o 2437-2013-PA/TC, de 16 de abril de 2014, fundamentos 25-61. 


\section{Conclusiones}

- $\quad$ La igualdad, según la concepción que tiene el Tribunal Constitucional, comprende dos ámbitos o dimensiones: como derecho fundamental (dimensión subjetiva) y como principio constitucional (dimensión objetiva). Su contenido se determina a partir de los siguientes mandatos: igualdad formal ante la ley (que admite la diferenciación), igualdad en la aplicación de la ley (que admite el apartamiento justificado del precedente) e igualdad material o sustancial (para que colectivos históricamente discriminados o invisibilizados puedan superar las barreras que históricamente los han excluido de las oportunidades para gozar o ejercer sus derechos. Asimismo, rige en las relaciones entre el Estado y las personas, y en las relaciones entre particulares) y el derecho a no ser discriminado (prohibición de discriminación).

- De la jurisprudencia constitucional abordada se advierte que, en el período objeto de análisis (2001-2016), el Tribunal Constitucional ha tenido un desarrollo bastante sólido del principio derecho de igualdad en sus dimensiones formal y sustancial, y en lo relativo a la prohibición de discriminación, hubo avances en relación con la discriminación directa e indirecta, pero solo a partir de la actual composición del Tribunal se ha la incorporado el concepto de discriminación por indiferenciación, interseccional (o múltiple) y la estructural (o sistémica). Los estándares relativos a estas tres últimas categorías aún requieren mayor desarrollo al resolver casos referidos a todos los grupos vulnerables, lo que no resta valor a su propia incorporación.

- La protección del derecho-principio de igualdad se presenta por niveles o grados, dado que se puede dar a través de procedimientos administrativos que es posible revisar a través de procesos judiciales $\mathrm{y}$, de forma reforzada, a través de los procesos constitucionales.

La aplicación judicial del principio-derecho de igualdad se condensa en el denominado test de igualdad (determinación del tratamiento diferente, determinación de la intensidad de la intervención en la igualdad y determinación de la finalidad y objetivo del tratamiento diferenciado) que incluye el principio de proporcionalidad (idoneidad, necesidad y proporcionalidad en sentido estricto o ponderación). 


\section{Bibliografía citada}

Alexy, Robert (2019): Ensayos sobre la teoría de los principios y el juicio de proporcionalidad. (Lima, Palestra Editores).

Bernal Pulido, Carlos (2005a): "El juicio de igualdad en la jurisprudencia de la Corte Constitucional", en su volumen El derecho de los derechos (Bogotá, Universidad Externado de Colombia), pp. 274-285.

(2006b): "La aplicación del principio de proporcionalidad en el juicio de igualdad. Comentario a la sentencia del Tribunal Constitucional del Perú N. 0045-2004-PI/TC", en Palestra del Tribunal Constitucional (№ 5), pp. 321-336.

(2007c): El principio de proporcionalidad y los derechos fundamentales (Madrid, CEPC).

Danisi, Carmelo (2011): "How far can the European Court of Human Rights go in the fight against discrimination? Defining new standards in its nondiscrimination jurisprudence", en International Journal of Constitutional Law (Vol. 9, № 3-4), pp. 793-807.

Díaz de Valdés, José Manuel (2019): Igualdad Constitucional y no discriminación (Valencia, Tirant lo Blanch).

Díaz Revorio, Francisco Javier (2003a): La interpretación constitucional de la ley. Las sentencias interpretativas del Tribunal Constitucional (Lima, Palestra Editores).

(2015b): Discriminación en las relaciones entre particulares (México, Tirant lo Blanch).

(2017c): "Las dimensiones constitucionales de la igualdad", en Pensamiento Constitucional (№ 22), pp. 21-60.

Esparza Reyes, Estefanía (2018): La igualdad como no subordinación. Una propuesta de interpretación constitucional (México, Tirant lo Blanch).

Granados Boza, Víctor (2018): “El principio constitucional de justicia e igualdad real y la acción afirmativa", en Cuestiones Constitucionales (№ 39), pp. 169-200. 
Havelková, Barbara y Möschel, Mathias (2019): “Anti-Discrimination Law in Civil Law Jurisdictions", en Oxford University Press, pp. 1-29.

Landa Arroyo, César (2010a): La fuerza normativa constitucional de los derechos fundamentales. Bazán, V. y C. Nash (editores) Justicia constitucional y derechos fundamentales (Montevideo, Fundación Konrad Adenauer), pp. 17-42.

(2011b): Derechos fundamentales y justicia constitucional (México, Porrúa).

(2018c): Derecho procesal constitucional (Lima, Fondo Editorial de la Pontificia Universidad Católica del Perú).

(2019d): Los derechos fundamentales en la jurisprudencia del Tribunal Constitucional 2008-2018. Segunda edición actualizada (Lima, Palestra Editores).

López Guerra, Luis (2001): El Poder Judicial en el Estado Constitucional (Lima, Palestra Editores).

Noguera Fernández, Albert (2014): La igualdad ante el fin del Estado social (Madrid, Sequitur).

Salomé Resurrección, Liliana (2017): “La discriminación y algunos de sus calificativos: directa, indirecta, por indiferenciación, interseccional (o múltiple) y estructural”, en Pensamiento Constitucional (№ 22), pp. 255-290.

\section{Normas jurídicas citadas}

Ley N. 28237, Código Procesal Constitucional. Diario El Peruano, 31 de mayo de 2004.

Constitución Política del Perú. Diario El Peruano, 31 de octubre de 1993

Constitución de la República de Ecuador. 20 de octubre de 2008.

\section{Jurisprudencia citada}

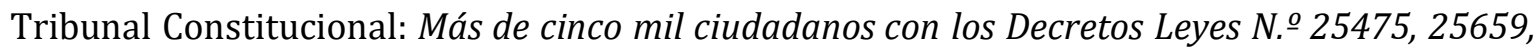
25708 y 25880 (demanda de inconstitucionalidad), Exp. N. 0010-2002-AI/TC, de 3 de enero de 2003. 
Tribunal Constitucional: Cámara Peruana de la Construcción con Quinta Sala Civil de la Corte Superior de Justicia de Lima (amparo), Exp. N. 00261-2003-AA/TC, de 26 de marzo de 2003.

Tribunal Constitucional: Cinco mil setenta y siete ciudadanos con el artículo $1^{o}$ de la Ley $N .^{o}$ 27633, modificatoria de la Ley N. 27143 (demanda de inconstitucionalidad), Exp. N.o 00182003-AI/TC, de 26 de abril de 2004.

Tribunal Constitucional: Manuel Anicama Hernández, con Cuarta Sala Civil de la Corte Superior de Justicia de Lima (amparo), Exp. N. 1417-2005-PA/TC, de 8 de julio de 2005.

Tribunal Constitucional: Colegio de Abogados del Cono Norte de Lima artículo $3^{\circ}$ de la Ley N. $^{o}$ 27466, (demanda de inconstitucionalidad), Exp. N. 0045-2004-PI/TC, de 29 de octubre de 2005.

Tribunal Constitucional: César Antonio Baylón Flores con Corte Superior de Justicia de Huaura (amparo), Exp. N. 0206-2005-PI/TC, de 28 de noviembre de 2005.

Tribunal Constitucional: Rosa Gambini Vidal con Sexta Sala Civil de la Corte Superior de Justicia de Lima (amparo), Exp. N. 5652-2007-PA/TC, de 6 de noviembre de 2008.

Tribunal Constitucional: Manuel Sales con Sala Especializada en Derecho Constitucional de la Corte Superior de Justicia de Lambayeque (amparo), Exp. N. ${ }^{\circ}$ 1604-2009-PA/TC, de 14 de octubre de 2009.

Tribunal Constitucional: ONG "Acción de Lucha Anticorrupción" con Ministerio de Salud (amparo), Exp. N. 2005-2009-PA/TC, de 16 de octubre de 2009.

Tribunal Constitucional: Corporación Pesquera Inca S.A.C. con Cuarta Sala Civil de la Corte Superior de Justicia de Lima (amparo), Exp. N. 2835-2010-PA/TC, del 13 de diciembre de 2011.

Tribunal Constitucional: Seis mil setecientos diecisiete ciudadanos con el Congreso de la

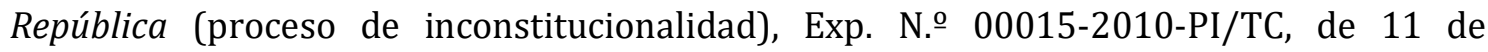
setiembre de 2012.

Tribunal Constitucional: Consorcio Requena con Sala Mixta de la Corte Superior de Justicia de

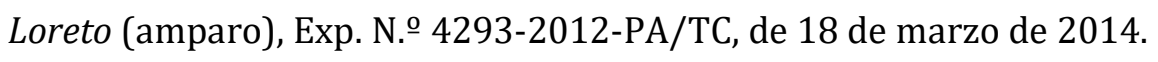


Tribunal Constitucional: Margarita Cósar Camacho con Quinta Sala Civil de la Corte Superior de Justicia de Lima (amparo), Exp. N. 2437-2013-PA/TC, de 16 de abril de 2014.

Tribunal Constitucional: Andrea Álvarez Villanueva con Sala Mixta Transitoria de Ate de la Corte Superior de Justicia de Lima (amparo), Exp. N. $01423-2013-\mathrm{PA} / \mathrm{TC}$, de 9 de diciembre de 2015.

Tribunal Constitucional: María Antonieta Callo con Segunda Sala Penal de Apelaciones de la Corte Superior de Justicia de Cusco (hábeas corpus), Exp. N. 2834-2013-PHC/TC, de 25 de enero de 2017.

Tribunal Constitucional: Duberlis Nina Cáceres con Sala Mixta de la Corte Superior de Justicia de Madre de Dios (amparo), Exp. N. 1272-2017-PA/TC, de 5 de marzo de 2019. 